Article

\title{
The Optimization of the Location and Capacity of Reactive Power Generation Units, Using a Hybrid Genetic Algorithm Incorporated by the Bus Impedance Power-Flow Calculation Method
}

\author{
Insu Kim 1
}

Electrical Engineering, Inha University, Incheon 22212, Korea; insu@inha.ac.kr

Received: 10 November 2019; Accepted: 2 January 2020; Published: 4 February 2020

\begin{abstract}
Dynamic and static reactive power resources have become an important means of maintaining the stability and reliability of power system networks. For example, if reactive power is not appropriately compensated for in transmission and distribution systems, the receiving end voltage may fall dramatically, or the load voltage may increase to a level that trips protection devices. However, none of the previous optimal power-flow studies for reactive power generation (RPG) units have optimized the location and capacity of RPG units by the bus impedance matrix power-flow calculation method. Thus, this study proposes a genetic algorithm that optimizes the location and capacity of RPG units, which is implemented by MATLAB. In addition, this study enhances the algorithm by incorporating bus impedance power-flow calculation method into the algorithm. The proposed hybrid algorithm is shown to be valid when applied to well-known IEEE test systems.
\end{abstract}

Keywords: bus impedance power-flow calculation; genetic algorithm; reactive power generation optimization

\section{Introduction}

Reactive power plays an important role in maintaining the stability and reliability of transmission and distribution power systems. As a consequence, various dynamic (synchronous generators, synchronous condensers, and solid-state devices) and static reactive power sources (capacitive and inductive compensators, as well as inverter-based distributed generators) have been deployed over the past few decades [1]. In particular, reactive power generation (RPG) units have been deployed at the optimal location for voltage control in transmission and distribution systems. If reactive power is not appropriately compensated, receiving ends may experience voltage variations outside $\pm 5 \%$ of the rated voltage, possibly leading to automatic tripping of protection devices and low power factors.

Optimally allocating RPG units is one of the optimal power flow (OPF) problems, and the solution has been sought by using meta-heuristic, search, and optimization algorithms. The former includes annealing and fuzzy clustering [2], the evolution approach [3], genetic algorithms (GAs) [4], krill herd algorithms [5], particle swarm optimization (PSO) [6], seeker algorithms [7], and whale optimization [8]. The search algorithms contain backtracking [9], cuckoo [10], differential [11], direct [12], and harmony search methods [13]. The optimization algorithms (as conventional methods) involve decomposition methods [1], dynamic programming [14], gradient-based optimization [15], interior-point methods [16], linear approximation [17], mixed integer programming [18,19], quadratic programming [20], teaching-based learning [21], and decision-making algorithms [22].

As renewable energy deployments increase, the optimal allocation of RPG units should take photovoltaic (PV) systems [23], wind turbine generators (WTGs) [24,25], and microgrids [26] into account. For example, the effect of optimally allocated distributed generation (DG) units on energy 
savings [27], generation resource allocation [28], distribution networks [29], peak load reduction [30], reliability [31], voltage and losses [32], and Volt/Var control and management [33] have been examined. In these studies, the optimally allocated DG units could improve the voltage profile, reduce peak load and energy losses of distribution networks, and improve reliability.

The GA approach of solving an optimization problem can find more desirable solutions to the objective function, as a result of the operations of mutation and crossover [34]. The GA can be also programmed relatively more easily than other algorithms. Thus, an OPF problem for DG (with the ability to control Volt/Var) has been solved by the GA [35]. That study optimized DG units in the IEEE 13- and 34-bus test feeders, using the GA that minimizes variations of each bus voltage and the installation costs of DG units. Static Var compensators (SVCs) are optimally allocated to reduce power losses and voltage deviation using the GA [36]. Recently, an RPG optimization problem in the IEEE 14and 57-bus test systems as input with interval uncertainties (i.e., real power losses) was solved by a GA [4]. An RPG optimization problem with DC transmission links and converters for high-voltage direct current (HVDC) systems added to the constraints was also solved by a GA [37]. In addition, an RPG optimization problem for a system that included PV, WTGs, converter models, and energy storage systems was solved by a GA [38]. However, neither of the previous studies optimized the location and capacity of RPG units by the bus impedance matrix power-flow calculation method with the constraint of varying demand. The bus impedance matrix method, which is useful for short-circuit studies, is usually not used, because it is difficult to apply to tap-changing transformers. Thus, an objective of this study is to enhance the bus impedance matrix power-flow method to model tap-changing transformers. The second objective is to present a hybrid GA that optimizes the location and capacity of RPG units using the proposed power-flow calculation method. The proposed GA implements scaled roulette wheel selection, single-point crossover, and single-position uniform mutation operation. The proposed hybrid GA is validated by optimizing the RPG units in the IEEE 14-, 30-, and 57-bus test systems. Since the test feeders include common power-flow analysis components (slack, $\mathrm{P}-\mathrm{Q}$, and $\mathrm{P}-\mathrm{V}$ buses, as well as generators, tap-changing transformers, constant power loads, capacitor banks, and lines), the proposed GA could improve the performance of GAs when applied to other test feeders.

\subsection{Contributions and Impacts of This Study}

The important results of this study are as follows:

(1) A GA that optimizes the location and capacity of RPG units with an objective function (which minimizes variation in voltage, the installation cost of RPG units, and losses), equal and unequal constraints, and varying demands is proposed.

(2) The proposed GA has an integrated bus impedance matrix power flow calculation method that models tap-changing transformers.

(3) Case studies performed with IEEE 14-, 30-, and 57-bus test systems demonstrate the validity of the proposed GA.

Since the case studies included buses, lines, loads, generators, shunt capacitors, tap-changing transformers, $\mathrm{P}-\mathrm{Q}, \mathrm{P}-\mathrm{V}$, and slack buses, the results show that the proposed power-flow calculation method can be used to analyze many different power system configurations. This study integrates the bus impedance power-flow calculation into a GA. As a result, the proposed hybrid GA can be also used for operating, planning, or upgrading transmission systems by optimally allocating RPG units. In particular, PV and WTGs able to control reactive power or with the capability of Volt/Var control management can be optimally allocated by the proposed hybrid GA.

\subsection{Structure of This Paper}

This paper is organized as follows: Section 2 discusses the bus impedance power flow method, Section 3 contains the proposed GA, Section 4 presents case studies, and Section 5 summarizes the paper's major conclusions. 


\section{Bus Impedance Power Flow Method}

The Newton-Raphson and fast-decoupled power-flow calculation methods that use the admittance matrix require the inverse of the Jacobian matrix. Such an inverse of the matrix can take a long time for a system with thousands or more nodes. Thus, this study proposes a power-flow calculation method that does not require the inverse of the Jacobian matrix, which is the main benefit of the proposed method. The proposed power-flow method evaluates the fitness of population members of the GA when optimally allocating RPG units. The detailed implementation of the GA is presented in the next section.

\subsection{Bus Impedance Matrix}

Figure 1 shows a power system network with $n$ nodes. The $n \times n$ impedance matrix $\left(Z_{b u s}\right)$ can represent the system as driving-point impedances (diagonal elements) and transfer impedances (off-diagonal elements). This study uses the well-known four rules that build the $Z_{b u s}$ matrix [39].

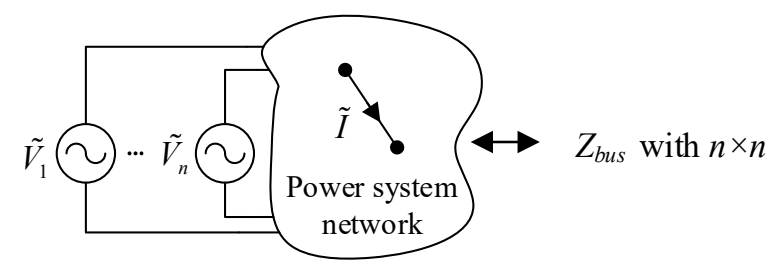

Figure 1. Power system network.

\subsection{Iterative Current Injection Method}

The iterative bus impedance power-flow calculation method was originally presented in [40]. The $Z_{b u s}$ matrix power-flow calculation method uses the following matrix form of Ohm's law for current that flows in each node and voltage induced to each node:

$$
\mathbf{V}^{(\mathbf{k})}=\mathbf{Z}_{\text {bus }} \mathbf{I}^{(\mathbf{k})}
$$

In Figure 2, the currents that flow to the constant power load are calculated by

$$
\mathbf{I}_{\text {load }}^{(\mathbf{k})}=\left(\frac{\mathbf{S}_{\text {load }}}{\mathbf{V}^{(\mathbf{k})}}\right)^{*}
$$

The current that flow to the constant current load are calculated by

$$
\mathbf{I}_{\text {load,I }}^{(\mathbf{k})}=\left|\left(\frac{\mathbf{S}_{\text {load }}}{\mathbf{V}_{\text {nom }}}\right)^{*}\right| \angle\left(\delta_{V^{(k)}}-\delta_{s}\right) .
$$

The currents that flow to the constant impedance load are calculated by

$$
I_{\text {load, },}^{(\mathbf{k})}=\frac{\mathbf{V}^{(\mathbf{k})}}{\left(\frac{V_{\text {nom }}^{2}}{S_{\text {load }}^{*}}\right)} .
$$

The currents that flow to the ground through parallel elements are also calculated by

$$
\mathbf{I}_{\text {parallel }}^{(\mathbf{k})}=\mathbf{Y}_{\text {parallel }} \mathbf{V}^{(\mathbf{k})} \text {. }
$$

The currents flowing to loads and the ground are added by

$$
\mathbf{I}^{(\mathbf{k})}=\mathbf{I}_{\text {load }}^{(\mathbf{k})}+\mathbf{I}_{\text {parallel }}^{(\mathbf{k})}+\mathbf{I}_{\text {line }}^{(\mathbf{k})} .
$$


The currents are also iteratively used in Equation (1). However, the currents in Equation (6) are estimated from the initial nominal voltage. That is, they do not take the voltage variation caused by loads, generators, shunt capacitors, and transformers into account. Therefore, Equations (1) and (6) are repeated until the following convergence:

$$
\Delta \mathbf{V}^{(\mathbf{k})}=\mathbf{V}^{(\mathbf{k})}-\mathbf{V}^{(\mathbf{k}-1)} .
$$

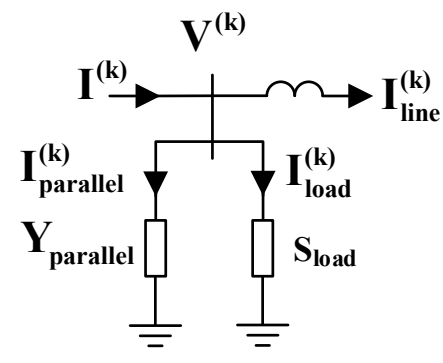

Figure 2. Currents that flow in a bus.

\subsection{Tap-Changing Transformer Model}

The bus impedance power-flow calculation method, originally presented in [40], is usually not used in power-flow studies, or the method is used in analyzing a system without transformers because the method cannot analyze tap-changing transformers. However, most transmission and distribution systems include tap-changing transformers to change the secondary-side voltage. Therefore, such a transformer should not be ignored in a power-flow calculation algorithm.

If a tap-changer with a turns ratio of $a$ is on the low-voltage (or secondary) side in Figure 3, the admittance matrix, $\mathbf{Y}_{\text {bus }}$, is

$$
\left[\begin{array}{c}
I_{m} \\
I_{n}
\end{array}\right]=\left[\begin{array}{cc}
Y_{e q}+Y_{m 0} & -a Y_{e q} \\
a Y_{e q} & -a^{2}\left(Y_{e q}+Y_{e x}\right)+Y_{n 0}
\end{array}\right]\left[\begin{array}{c}
V_{m} \\
V_{n}
\end{array}\right]=\mathbf{Y}_{\mathbf{b u s}} \mathbf{V}
$$

where $Y_{m 0}$ and $Y_{n 0}$ are the line capacitances beside the transformer.

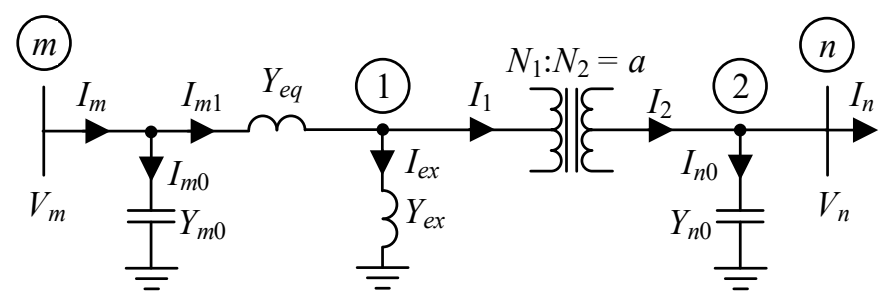

Figure 3. Transformer with a secondary-side tap.

To model the tap-changing transformer depicted in Figure 3 in the proposed method, this study proposes decomposing the transformer model into two parts: the series and parallel elements in Figure 4.

$$
\begin{gathered}
I_{m}=a Y_{e q}\left(V_{m}-V_{n}\right)+\left((1-a) Y_{e q}+Y_{m 0}\right) V_{m} \\
I_{n}=a Y_{e q}\left(V_{m}-V_{n}\right)-\left(\left(a^{2}-a\right) Y_{e q}+a^{2} Y_{e x}+Y_{n 0}\right) V_{n} .
\end{gathered}
$$




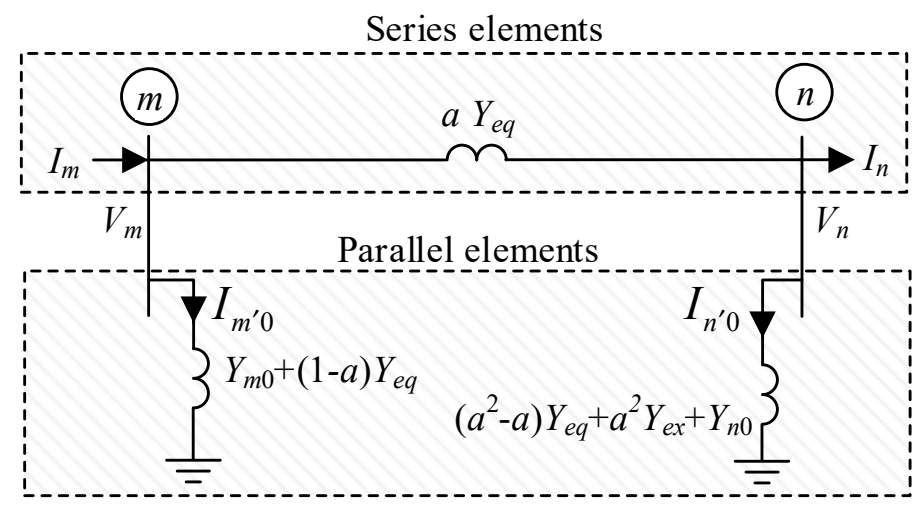

Figure 4. Equivalent model of a transformer with a secondary-side tap.

The proposed method builds the $\mathbf{Z}_{\text {bus }}$ matrix of the series elements in Figure 4. The matrix also includes lines without transformers. The final $\mathbf{Z}_{\text {bus }}$ matrix is used in (1) during iterations. Additionally, the proposed method builds the $\mathbf{Y}_{\text {bus }}$ matrix of the parallel elements in Figure 4, calculates $I_{m^{\prime} 0}$ and $I_{n^{\prime} 0}$ by (5), and adds them to Equation (6). As a result of this compensation $\left(I_{m^{\prime} 0}\right.$ and $\left.I_{n^{\prime} 0}\right)$, the proposed method can solve the problem of applying the conventional bus impedance, matrix power-flow calculation method to tap-changing transformers.

\section{Genetic Algorithm}

Optimal allocation of the capacity and location of RPG units can be treated as an optimization problem. Thus, this study presents a GA that includes the proposed power-flow calculation method. The GA finds one or more RPG units and their capacities to minimize the following objective function.

\subsection{Objective Function}

The proposed GA defines, as its objective function, the minimizing of the weighted sum of three parameters: variation in voltage to a set value (e.g., 1.0 p.u.), the installation cost of RPG units, and total losses.

$$
\begin{gathered}
C_{V}=\sum_{h=1}^{H} \sum_{i=1}^{N}\left|V_{\text {set }}-V_{i, h}^{(k)}\right|, \\
C_{R P G}=\sum_{i=1}^{R} N_{R P G, i} C_{\text {gen }, i}, \\
C_{\text {Loss }}=\sum_{h=1}^{H} \sum_{i=1}^{B}\left|S_{\text {Loss }, i, h}\right| \\
\text { Objective }=\text { Minimize }\left(W_{V} \frac{C_{V}}{C_{V, \text { max }}}+W_{R P G} \frac{C_{R P G}}{C_{R P G, \text { max }}}+W_{\text {Loss }} \frac{C_{\text {Loss }}}{C_{\text {Loss }, \text { max }}}\right),
\end{gathered}
$$

subject to

$$
\begin{gathered}
V_{\text {min }}^{(k)} \leq V_{i}^{(k)} \leq V_{\text {max }}^{(k)} \text { for } i=1, \ldots, N \\
\operatorname{Tap}_{\text {min }} \leq \operatorname{Tap}_{i} \leq \operatorname{Tap}_{\text {max }} \text { for } i=1, \ldots, T \\
Q_{R P G, \text { min, } i}^{(k)} \leq Q_{R P G, i}^{(k)} \leq Q_{R P G, \max , i}^{(k)} \text { for } i=1, \ldots, R
\end{gathered}
$$

\subsection{Optimization Variables}

To optimally allocate the capacity and location of RPG units, the following optimization variables are defined. 
(1) Capacity: the capacity of an RPG unit is optimally determined with the following constraint.

$$
\mathrm{S}_{\min , i} \leq \mathrm{S}_{i} \leq \mathrm{S}_{\max , i} \text { for } i=1, \ldots, R
$$

(2) Location: RPG units can be connected to any bus, except the slack bus.

(3) Demand: the optimization of RPG units should take continuously varying demands into account during the optimization period. Thus, this study collected the typical load profile data in Figure 5 from [41]. The data show a peak demand of 1.0 p.u. at 15:00, and a load factor of 0.68 . These data are used as input for GA.

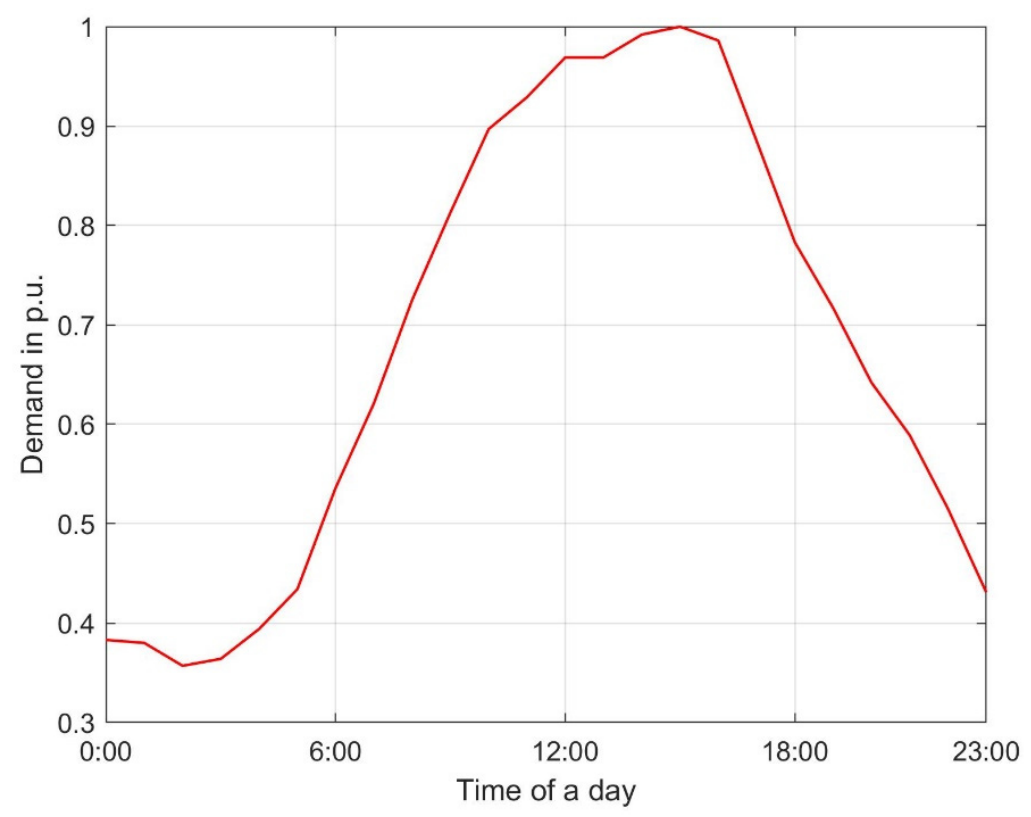

Figure 5. Typical demand data.

\subsection{Genetic Algorithm}

(1) Initialization: the GA initializes offspring members of the first generation with uniform random numbers. The offspring, $O$, is defined by

$$
O=\left\{\left[x_{i}, y_{i}\right] \mid x_{i} \in A, 0 \leq y_{i} \leq \mathrm{S}_{\max }\right\} \text { for } i=1, \ldots, M
$$

where $A=\left\{a_{i} \mid a_{i}\right.$ is a bus, excluding a slack bus $\}$ and $S_{\max }$ represents maximum capacity.

(2) Fitness and reproduction: the objective function (14) calculates a fitness score for each offspring member. A normalized geometric ranking selection scheme is used [42]. A lower geometric rank $\left(R_{i}\right)$ means a lower objective function value. Each slot size of a scaled roulette wheel is calculated by

$$
P_{i}=\frac{p(1-p)^{R_{i}-1}}{1-(1-p)^{M}} \text { for } i=1, \ldots, M,
$$

where $p$ is the probability that produces the fittest offspring, and $P_{i}$ is the probability of the slot size of the scaled roulette wheel.

Subsequently, the GA distributes random numbers to the scaled roulette wheel's slots, according to slot size (probability), and reproduces offspring members according to the number of random numbers that belong to each slot. This means that offspring with higher fitness in their objective function have a higher selection probability. 
(3) Crossover and mutation: an arithmetic crossover operation that combines two offsprings $\left(O_{i}\right.$ and $O_{j}$ ) is performed in Figure 6, so it produces new offsprings: $O_{i}{ }^{\prime}$ and $O_{j}{ }^{\prime}$. To avoid convergence to a local minimum, a new offspring member, $O_{k}{ }^{\prime}$, is also generated by single-position uniform mutation in Figure 7.

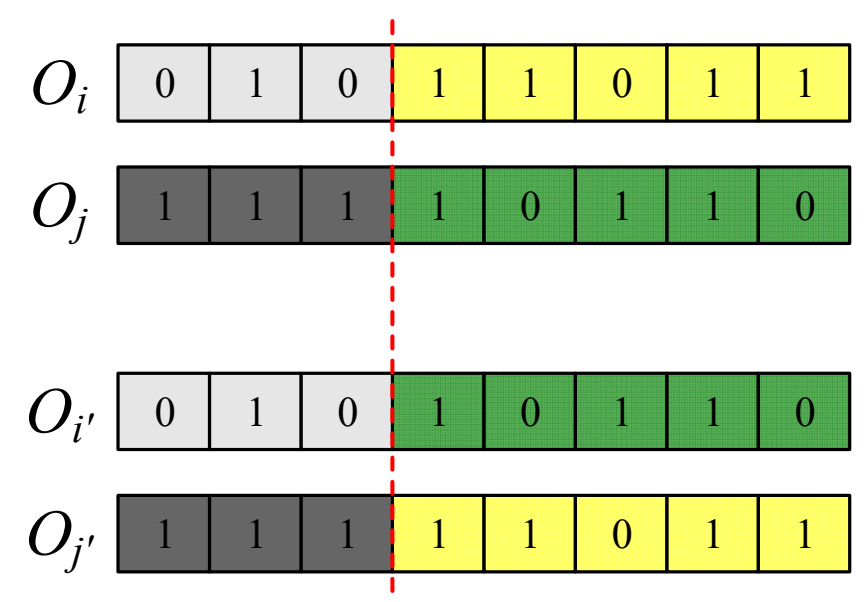

Figure 6. Single-point crossover operation.

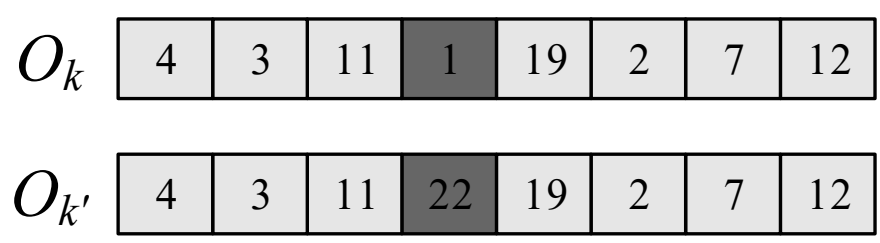

Figure 7. Single-position uniform mutation.

Figure 8 shows the detailed workflow of the proposed algorithms. The proposed GA calculates the probability of each slot of the scaled roulette wheel, generates random numbers on the wheel, counts the number of random numbers that belong to each slot, and reproduces offspring members. The detailed parameters for the proposed GA are presented in the following case studies. 


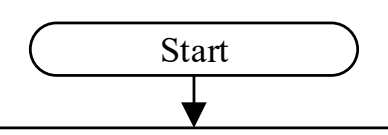

Read the data related to the objective function:

1) Weighting factors, RPG unit installation costs, and worst case costs.

2) Constraints: $V_{\min }, V_{\max }, P_{\min }, P_{\max }, Q_{\min }$, and $Q_{\max }$.

3) GA parameters: $p, P_{c}, P_{m}$, and the number of populations and generations.

4) Read load profile data.
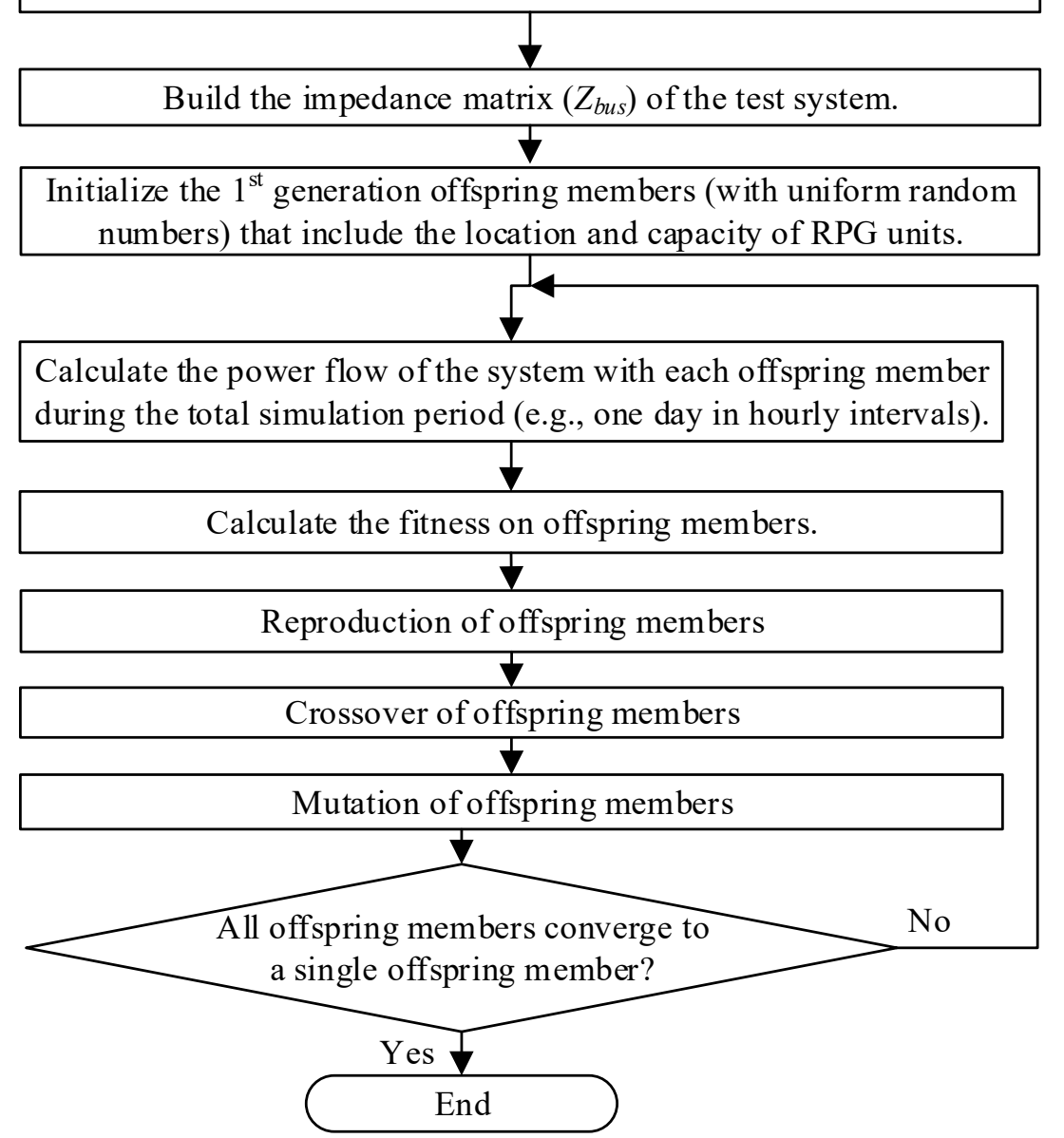

Figure 8. Workflow of the proposed method.

\section{Case Studies}

\subsection{Validation of Power-Flow Calculation Method}

To verify the proposed power-flow calculation algorithm, this case study calculates the power flow of the IEEE 14-bus system in Figure $9[43,44]$. The system includes 14 buses, 1 slack bus $\left(1.0 \angle 0^{\circ}\right), 4$ $\mathrm{P}-\mathrm{V}$ buses (a magnitude of voltage of 1.0 p.u.), 11 loads (in total: $P+j Q=259+j 73.5 \mathrm{MVA}$ ), 1 shunt capacitor ( $j 0.19$ p.u.), 1 generator (with $40 \mathrm{MW}$ ), and three tap-changing transformers (buses 4-7, 4-9, and 5-6). The other detailed system data are available in [43,44].

The results produced by the proposed bus impedance, Newton-Raphson, Gauss-Seidel, and decoupled power-flow calculation methods implemented in MATLAB show consistency with one another. The detailed voltage profile data are presented in the Appendix A. For example, a tap-changing transformer between buses 4 and 7 (with a transformer turns ratio of 0.978 ) modeled by the proposed power-flow method increases the primary side voltage of $0.95433 \angle-11.645^{\circ}$ p.u. to the secondary side 
voltage of $0.98343 \angle-15.117^{\circ}$ p.u. Figure 10 presents a convergence curve of the voltage of bus 7 , or the secondary side voltage of the tap-changing transformer, which reaches $0.98343 \angle-15.117^{\circ}$ p.u.

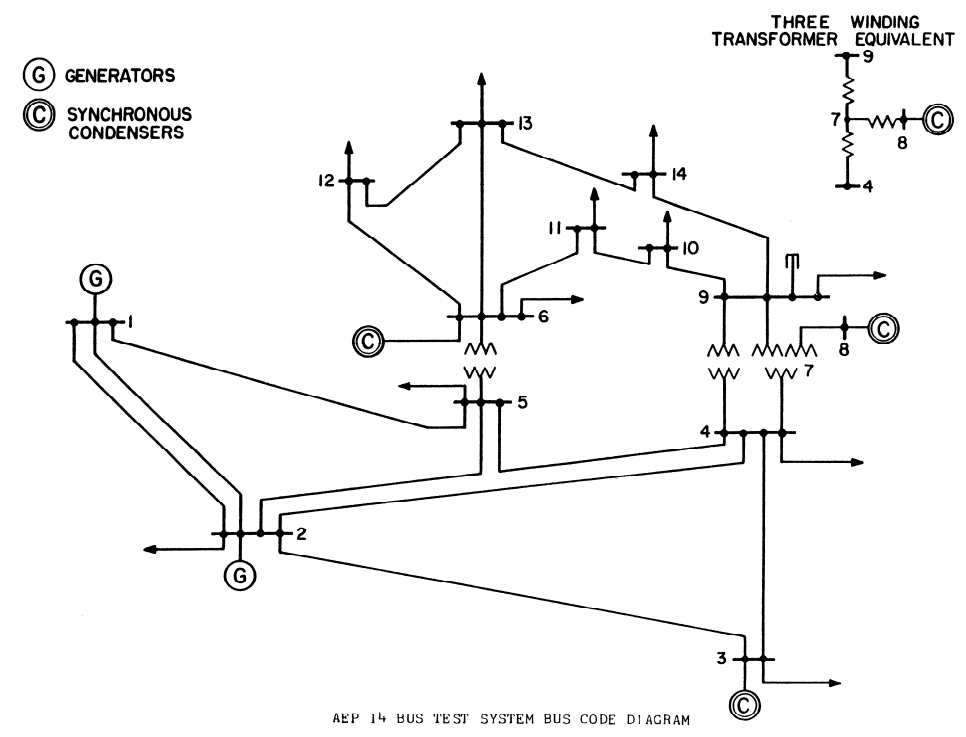

Figure 9. IEEE 14-bus system [43,44].

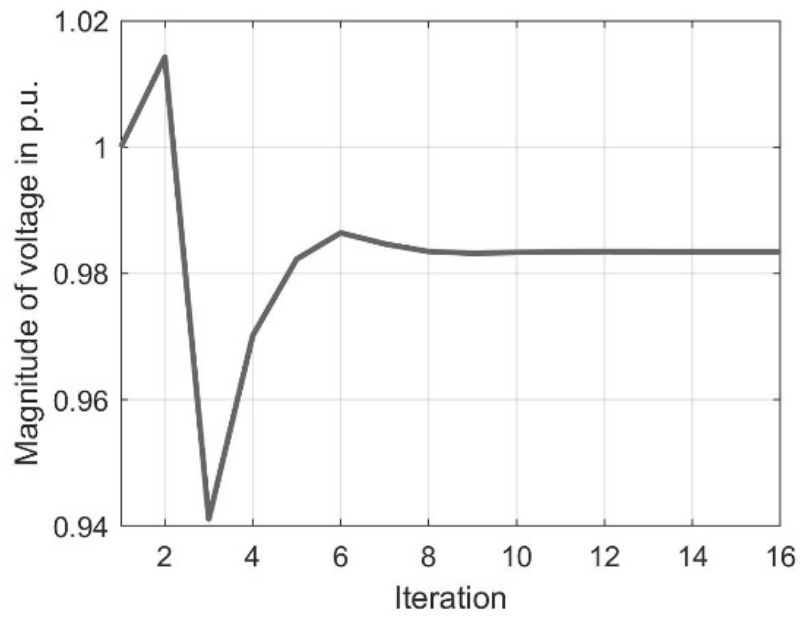

(a) Magnitude

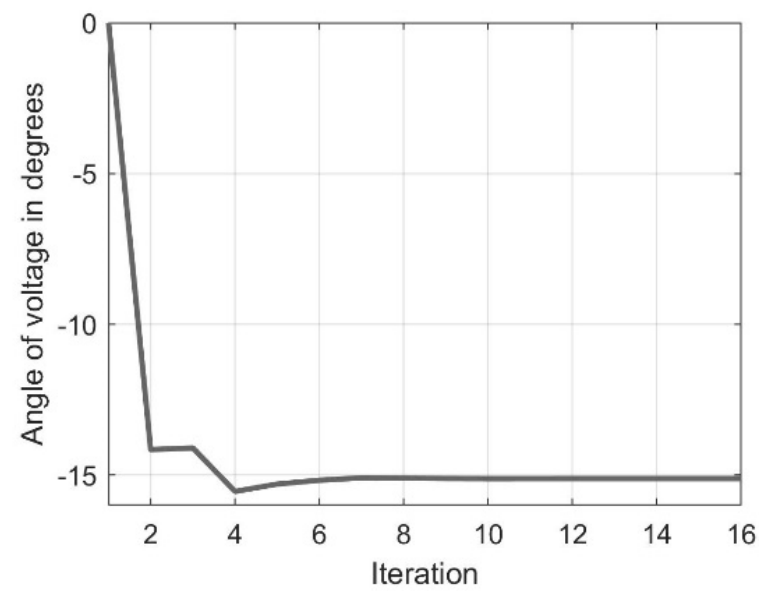

(b) Angle

Figure 10. Convergence of the voltage of bus 7 . 
Figure 11 shows the IEEE 30-bus test system [44,45]. The system includes a slack bus, five P-V buses, two shunt capacitors, twenty-one loads, and four tap-changing transformers. The detailed system data are available in $[44,45]$. Tables A1 and A2, presented in the Appendix A compare the power-flow calculation results determined by the proposed method to those produced by the Newton-Raphson, Gauss-Seidel, and decoupled power-flow calculation methods implemented in MATLAB. The results show good consistency with each other. As the third validation, Figure 12 shows the power-flow calculation results of the IEEE 57-bus test system, determined by the proposed method, to those produced by the Newton-Raphson and Gauss-Seidel methods. The detailed system data are available in $[44,46]$. The results show consistency with each other.

Since the test systems contains typical transmission system elements (i.e., loads, slack, $\mathrm{P}-\mathrm{V}, \mathrm{P}-\mathrm{Q}$ buses, shunt capacitors, generators, and tap-changing transformers), the proposed power-flow method can be integrated into the proposed GA.

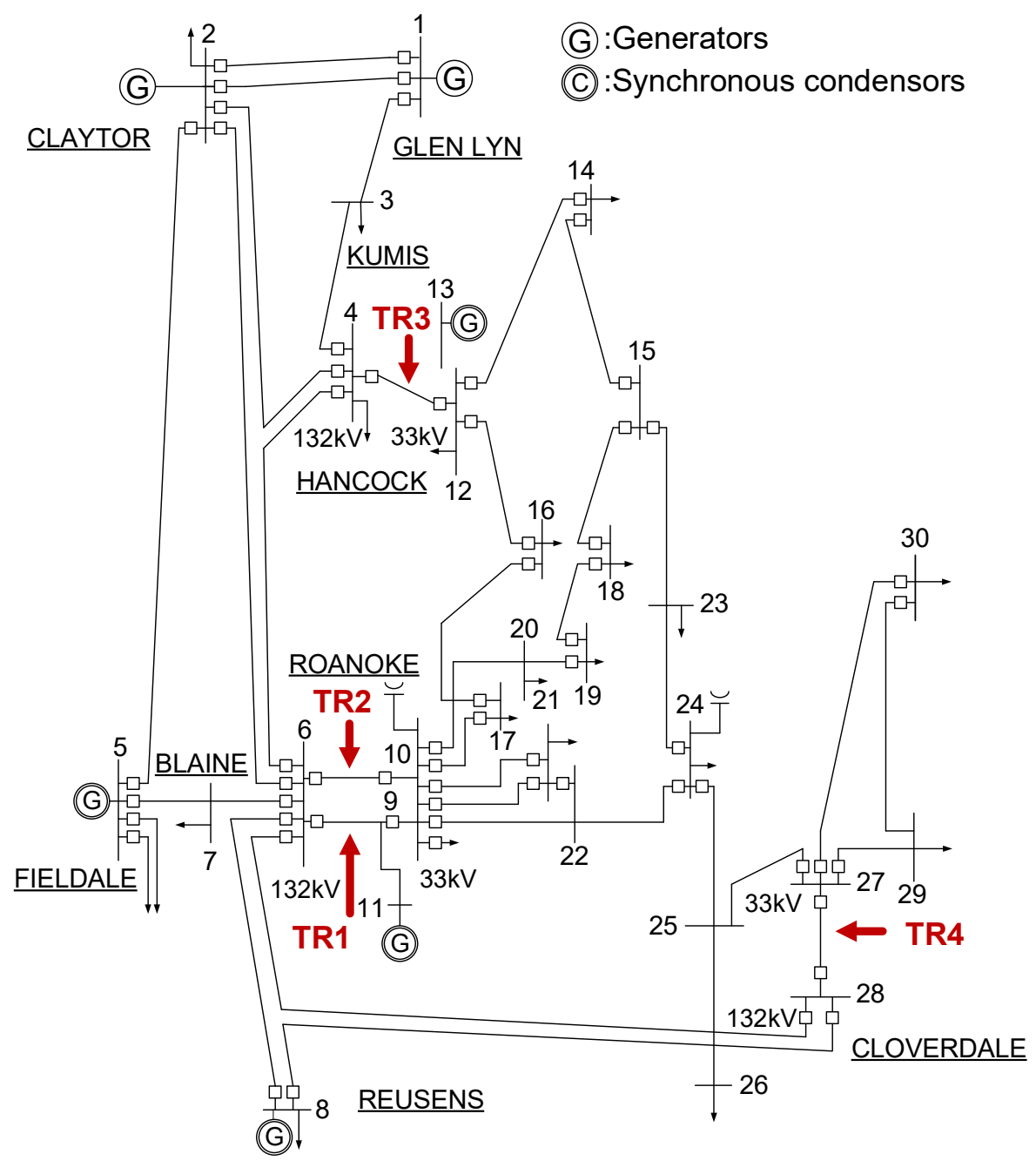

Figure 11. IEEE 30-bus system [44,45]. 


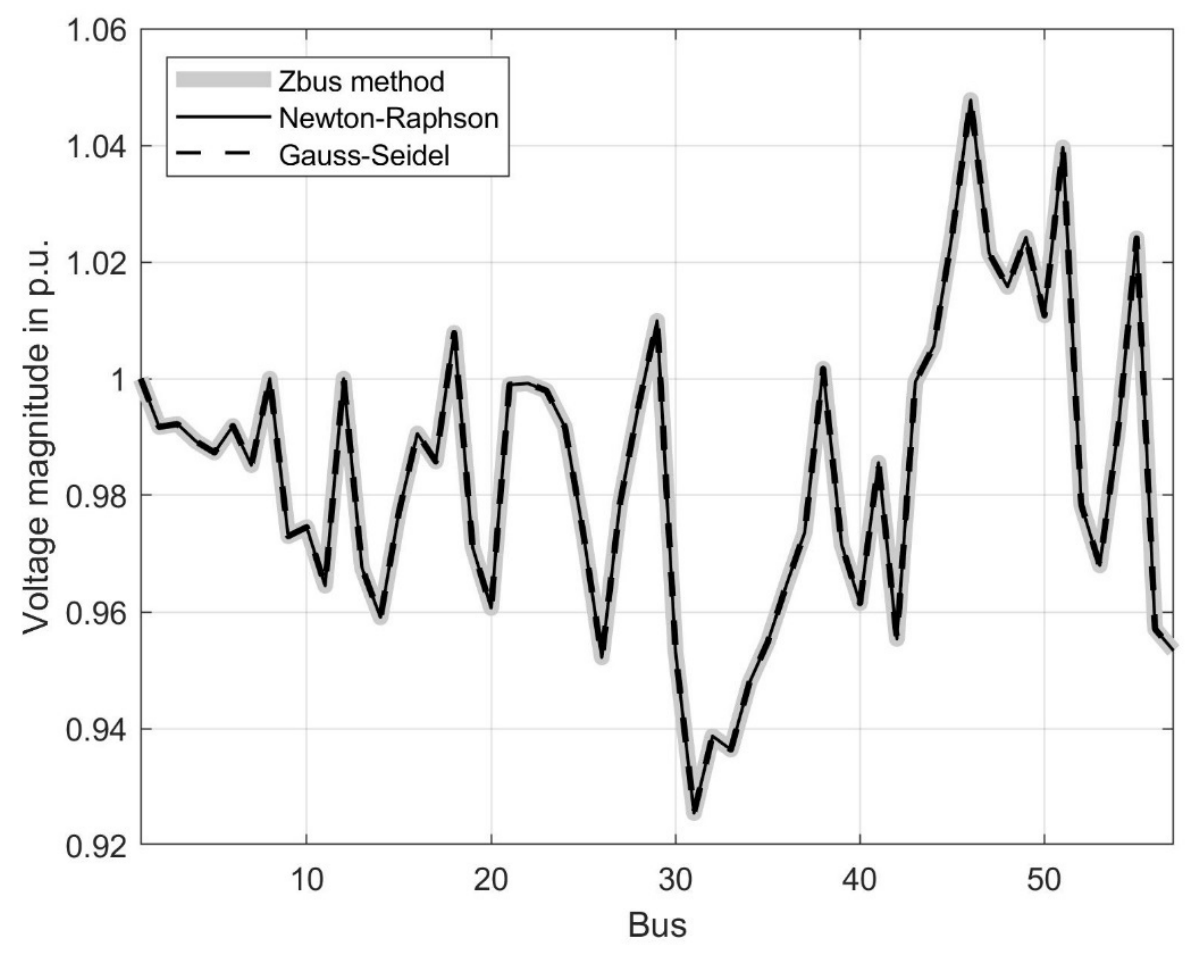

Figure 12. Voltage profile of the IEEE 57-bus system, in p.u.

\subsection{Validation of the Genetic Algorithm}

To find the optimal location and capacity of RPG units, this case study was run with the following assumptions:

(1) The maximum capacity of an RPG unit is 100\% of the base MVA of the system (i.e., 100 MVA);

(2) RPG units can be connected to all buses except the slack bus;

(3) The weighting factors in the objective function are equal;

(4) The nominal voltage of the slack and $\mathrm{P}-\mathrm{V}$ buses is set to $1 \angle 0^{\circ}$ p.u.

Table 1 presents the parameters of the GA. The parameters are determined by trial and error optimization [34,47-49]. To validate the proposed GA implemented in MATLAB, this case study was configured to optimally allocate RPG units in the IEEE 14- and 30-bus systems [43-46].

Table 1. Parameters of the genetic algorithm (GA).

\begin{tabular}{ccc}
\hline Operation & Method & Parameter \\
\hline Reproduction $[34,47,49]$ & $\begin{array}{c}\text { Probability that produces the fittest } \\
\text { offspring (scaled roulette wheel) }\end{array}$ & $p=0.001$ \\
\hline Crossover [34,47,49] & Arithmetic crossover per offspring & $P_{c}=1.0$ \\
\hline Mutation [34,47,49] & Uniform mutation & $P_{m}=0.1$ \\
\hline Experimental data [47] & The number of populations & 5000 \\
\cline { 2 - 3 } & The number of generations & 100 \\
\hline
\end{tabular}

\subsubsection{IEEE 30-Bus System}

As the first case study, this study optimally allocates RPG units in the IEEE 30-bus system in Figure 11. The proposed hybrid GA optimally allocates nine RPG units, with their total capacity of 183 MVA (47 MVA on bus 5, 32 MVA on bus 7, 56 MVA on bus 8, 7 MVA on bus 13, 11 MVA on bus 15, 5 MVA on bus 19,15 MVA on bus 21,5 MVA on bus 26 , and 5 MVA on bus 30 ), at an objective function 
of 0.05939 . To verify the ability of the proposed method to find an optimal solution, Figure 13 depicts the standard deviation of the objective function for offspring members over multiple generations. Since the variation converges to zero, the proposed GA determines the fittest single offspring member (i.e., a solution to the optimization problem). Figures 14 and 15 examine the effect of optimally allocated RPG units in the IEEE 30-bus system on voltage magnitude (Figure 14) and losses (Figure 15). The PRG units optimally allocated by the proposed hybrid GA provide less variation in voltage than the case that is not optimized, and reduce losses.

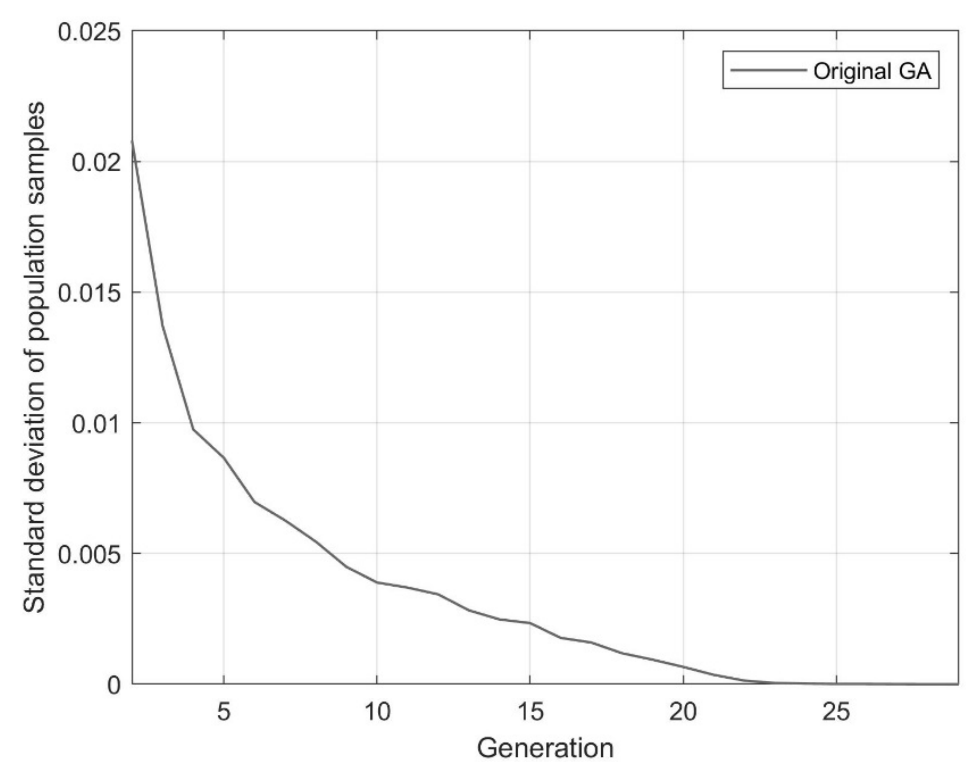

Figure 13. Standard deviation of the objective function of population members for each generation.

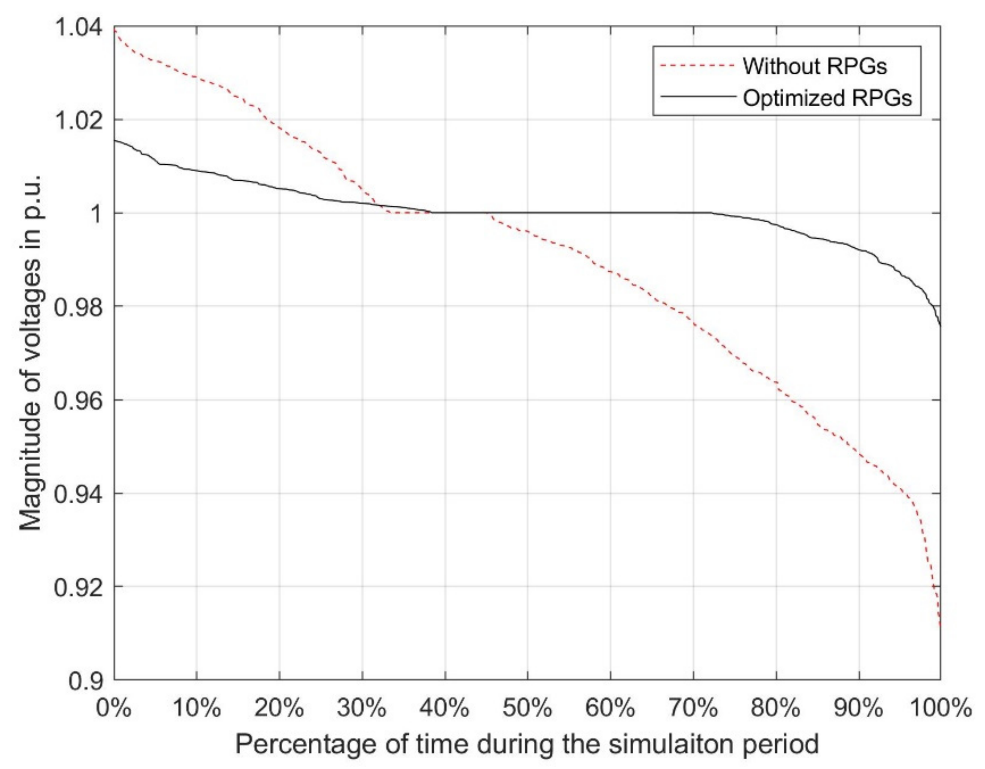

Figure 14. Voltage profile improvement in the IEEE 30-bus system. 


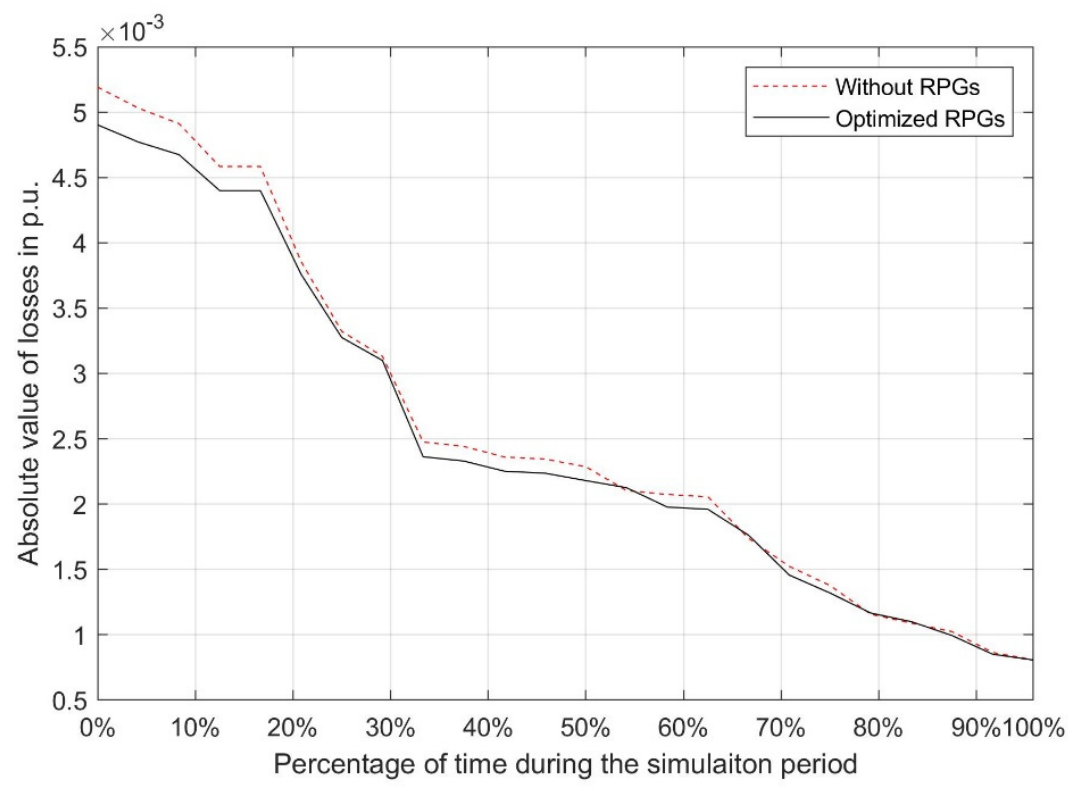

Figure 15. Loss reduction in the IEEE 30-bus system.

\subsubsection{IEEE 14-Bus System}

This study optimizes the capacity and location of RPG units in the IEEE 14-bus system in Figure 9. For the IEEE 14-bus system, the proposed GA optimally allocates six RPG units, with a total capacity of 90 MVA (53 MVA in bus 3, 11 MVA in bus 7, 8 MVA in bus 10, 2 MVA bus 12, 7 MVA in bus 13, and 9 MVA in bus 14), in order to minimize variation in voltage, the installation cost of RPG units, and losses. Figure 16 depicts the objective function's standard deviation for offspring members over multiple generations when the proposed GA finds a solution with an objective function of 0.07735 . Since the variation converges to zero, the proposed GA determines the fitter single offspring member (i.e., a solution to the optimization problem). Figures 17 and 18 present the effect of optimally allocated RPG units in the test system on voltage magnitude and losses. The PRG units optimally allocated by the proposed hybrid GA provide less variation in voltage than the case that is not optimized, and reduce losses.

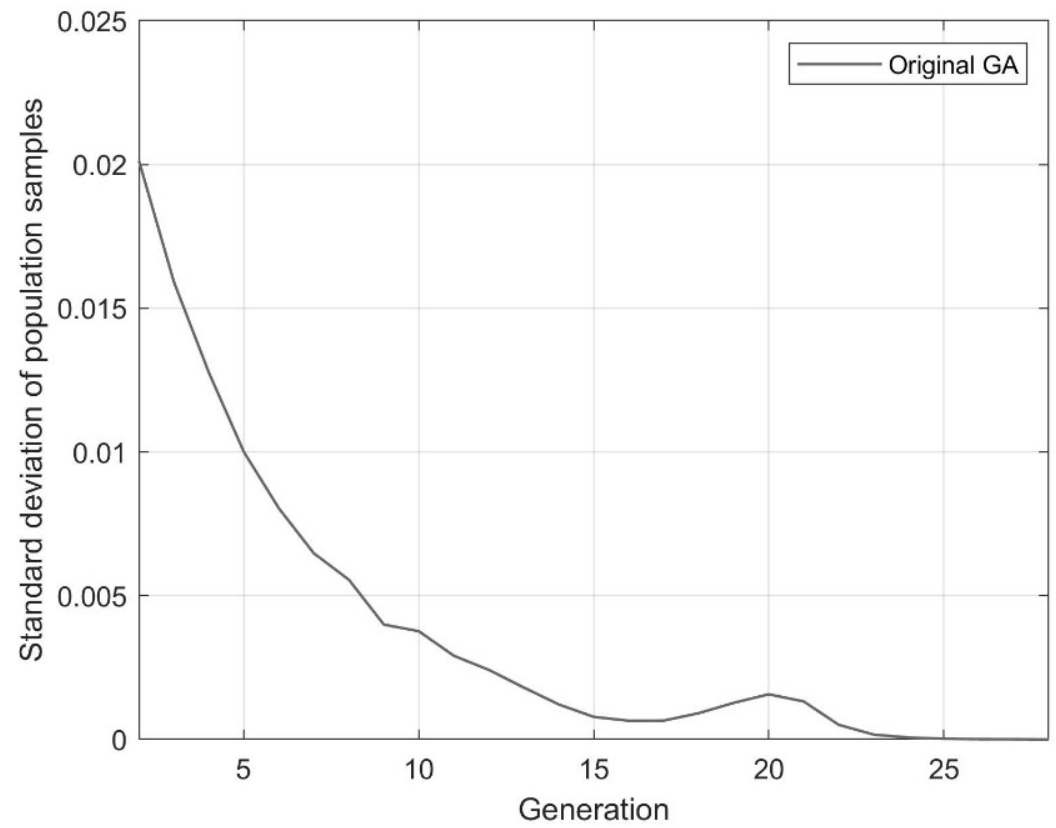

Figure 16. Standard deviation of the objective function of population members for each generation. 


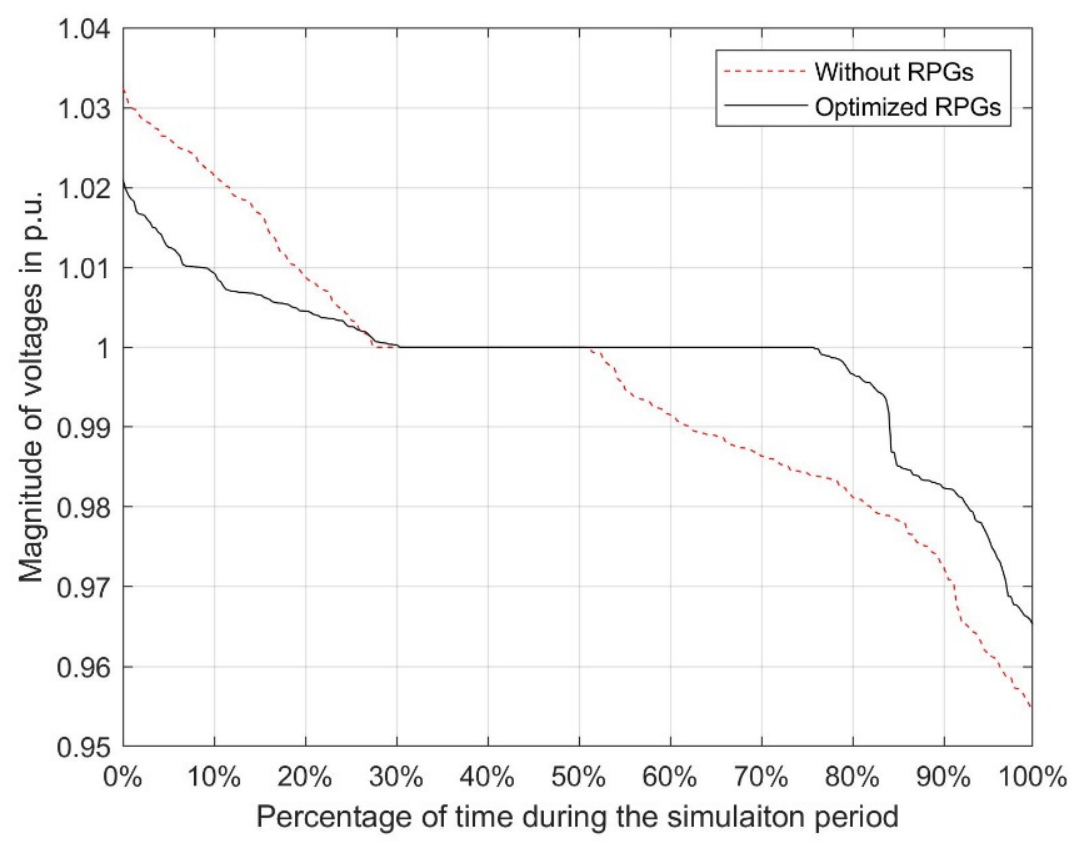

Figure 17. Voltage profile improvement in the IEEE 14-bus system.

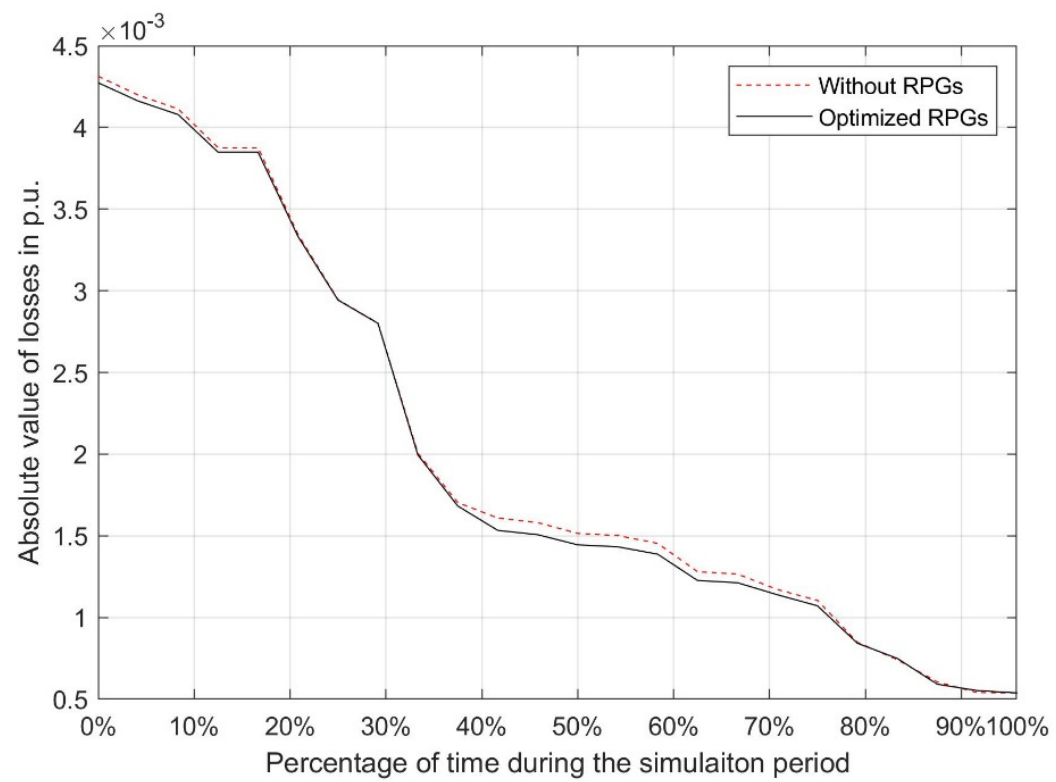

Figure 18. Loss reduction in the IEEE 14-bus system.

\section{Conclusions}

The objective of this study was to propose a hybrid algorithm that can model tap-changing transformers and optimize the location and capacity of RPG units for systems having these transformers. To achieve this objective, the study proposed a hybrid GA that incorporates bus impedance power-flow calculation. The proposed hybrid algorithm successfully calculated power flow in the well-known IEEE test systems (i.e., IEEE 14-, 30-, and 57-bus systems), and optimized the location and capacity of RPG units in the IEEE 14- and 30-bus systems.

Since the IEEE test systems include various power system elements (e.g., loads, slack, P-V, P-Q buses, shunt capacitors, generators, and tap-changing transformers), the proposed power-flow method can calculate the power flow of a variety of system configurations. The proposed hybrid algorithm can be also used for operating, planning, or upgrading transmission systems by optimally adding RPG units. PV and WTGs able to control reactive power can be optimally allocated by the proposed 
hybrid GA. However, the proposed algorithm is based on per-phase analysis, because transmission systems are usually assumed to be balanced. The algorithm could be extended to three-phase systems in future work.

Funding: This work was funded by Inha University research grant number 60140-01. The APC was funded by Inha University.

Conflicts of Interest: None conflicts of interest.

\section{Nomenclature}

\section{Abbreviations}

DG: distributed generation

GA: genetic algorithm

HVDC: high-voltage direct current

OPF: optimal power flow

p.u.: per unit

PV: photovoltaic

RPG: reactive power generation

SVC: static Var compensator

WTG: wind turbine generator

\section{Variables}

$A:\left\{a_{i} \mid a_{i}\right.$ is a bus, excluding a slack bus $\}$

$B$ : the number of branches

$C_{\text {Loss: }}$ : cost function for branch losses

$C_{R P G}:$ cost function for reactive power generation installation

$C_{V}$ : cost function for voltage variation

$C_{L o s, \text { max }}, C_{R P G, \max }$, and $C_{V, \text { max }}$ : worst case costs for losses, reactive power generator installation, and voltage variation

$C_{\text {gen, }, i}$ : generation cost of unit $i$ in $\$ / \mathrm{kW}$

$\delta_{V^{(k)}}$ : angle of the voltage at iteration $k\left(\mathbf{V}^{(\mathbf{k})}:\left|\mathrm{V}^{(k)}\right| \angle \delta_{V^{(k)}}\right)$

$\delta_{s:}$ angle of the scheduled complex power $\left(\mathbf{S}_{\text {load }}: P+j Q:|S| \angle \delta_{S}\right)$

$H$ : total simulation period

$\mathbf{I}^{(\mathbf{k})}$ : currents that flow in each node at iteration $k$

$\mathbf{I}_{\text {line }}^{(\mathbf{k})}$ : currents that flow in a line at iteration $k$

$\mathbf{I}_{\text {load }}^{(\mathbf{k})}$ : currents that flow to constant power loads in each node at iteration $k$

$\mathbf{I}_{\text {load, II }}^{(\mathbf{k})}$ : currents that flow to constant current loads in each node at iteration $k$

$\mathbf{I}_{\text {load, }}^{\mathbf{k})}$ : currents that flow to constant impedance loads in each node at iteration $k$

$I_{m}$ and $I_{n}$ : currents that flow in buses $m$ and $n$

$I_{e x}$ : excitation current of a tap-changing transformer

$\mathbf{I}_{\text {parallel }}^{(\mathbf{k})}$ : currents that flow through parallel elements

$N$ : the number of buses

$M$ : the number of offspring members

$N_{R P G, i}:$ nameplate capacity of reactive power generator $i$

$O$ : offspring member in a generation

$Q_{R P G, i}^{(k)}$ : output of reactive power generator $i$ at iteration $k$

$Q_{R P G, \min , i}^{(k)}$ and $Q_{R P G, \max , i}^{(k)}:$ minimum and maximum outputs of reactive power generator $i$ at iteration $k$

$p$ : probability that produces the fittest offspring

$P_{i}$ : probability of the slot size of the scaled roulette wheel

$R$ : the number of reactive power generators

$R_{i}$ : geometric rank of offspring member $i$ from 1 to $M$

$\mathrm{S}_{i}$ : nameplate capacity of a reactive power generation unit $i$ 
$\mathrm{S}_{\min , i}$ : minimum nameplate capacity of a reactive power generation unit $i$

$\mathrm{S}_{\max , i}$ : maximum nameplate capacity of a reactive power generation unit $i$

$S_{\text {Loss }, i, h}$ : losses of transmission line (or branch) $i$ at period $h$

$\mathrm{S}_{\text {load }}$ : complex power of loads connected to each node: $P+j Q:|S| \angle \delta_{S}$

$T$ : the number of tap-changing transformers

Tap $_{i}$ : tap position of transformer $i$

$\mathrm{Tap}_{\min }$ and Tap ${ }_{\max }$ : minimum and maximum tap positions

$\mathrm{Tap}_{\min }$ and Tap $\mathrm{max}_{\text {max }}$ minimum and maximum tap positions

$\mathbf{V}^{(\mathbf{k})}$ : voltages induced in each node at iteration $k$

$\mathrm{V}_{i, h}^{(k)}$ : voltage (magnitude) of bus $i$ at period $h$ and iteration $k$

$V_{m}$ and $V_{n}$ : voltages of buses $m$ and $n$

$\mathbf{V}_{\text {nom: }}$ magnitude of the nominal (or rated) voltage

$\mathrm{V}_{\text {set }}$ : set voltage magnitude of a reactive power generation unit

$x_{i}$ : location to which a reactive power generation unit can be connected

$W_{L o s s}, W_{R P G}$, and $W_{V}$ : weighting factors for losses, reactive power generator installation cost, and voltage

variation, respectively

$\mathrm{Y}_{\text {bus }}$ : bus admittance matrix

$Y_{e q}$ : series admittance of a tap-changing transformer

$Y_{e x}$ : excitation admittance of a tap-changing transformer

$y_{i}$ : capacity of a reactive power generation unit

$Y_{m 0}$ and $Y_{n 0}$ : admittances of buses $m$ and $n$ connected the ground

$Y_{\text {parallel }}$ : admittance matrix of parallel elements connected to the ground

$Z_{\text {bus }}$ or $\mathbf{Z}_{\text {bus }}$ : bus impedance matrix

\section{Appendix A}

Table A1 compares power-flow calculation results determined by the proposed $Z_{b u s}$ method to those produced by the Newton-Raphson, Gauss-Seidel, and decoupled power-flow calculation methods implemented in MATLAB.

Table A1. Voltage profile of the IEEE 14-bus system (in p.u.).

\begin{tabular}{ccccc}
\hline Bus & $Z_{\text {bus }}$ Method & Newton-Raphson & Gauss-Seidel & Decoupled \\
\hline 1 & $1.00000 \angle 0.000^{\circ}$ & $1.00000 \angle 0.000^{\circ}$ & $1.00000 \angle 0.000^{\circ}$ & $1.00000 \angle 0.000^{\circ}$ \\
\hline 2 & $0.98681 \angle-5.706^{\circ}$ & $0.98681 \angle-5.706^{\circ}$ & $0.98681 \angle-5.706^{\circ}$ & $0.98681 \angle-5.706^{\circ}$ \\
\hline 3 & $0.96106 \angle-14.609^{\circ}$ & $0.96106 \angle-14.609^{\circ}$ & $0.96106 \angle-14.609^{\circ}$ & $0.96106 \angle-14.609^{\circ}$ \\
\hline 4 & $0.95433 \angle-11.645^{\circ}$ & $0.95433 \angle-11.645^{\circ}$ & $0.95433 \angle-11.645^{\circ}$ & $0.95433 \angle-11.645^{\circ}$ \\
\hline 5 & $0.95627 \angle-9.917^{\circ}$ & $0.95627 \angle-9.917^{\circ}$ & $0.95627 \angle-9.917^{\circ}$ & $0.95627 \angle-9.917^{\circ}$ \\
\hline 6 & $1.00000 \angle-16.203^{\circ}$ & $1.00000 \angle-16.203^{\circ}$ & $1.00000 \angle-16.203^{\circ}$ & $1.00000 \angle-16.203^{\circ}$ \\
\hline 7 & $0.98343 \angle-15.117^{\circ}$ & $0.98343 \angle-15.117^{\circ}$ & $0.98343 \angle-15.117^{\circ}$ & $0.98343 \angle-15.117^{\circ}$ \\
\hline 8 & $1.00000 \angle-15.117^{\circ}$ & $1.00000 \angle-15.117^{\circ}$ & $1.00000 \angle-15.117^{\circ}$ & $1.00000 \angle-15.117^{\circ}$ \\
\hline 9 & $0.97853 \angle-16.937^{\circ}$ & $0.97853 \angle-16.937^{\circ}$ & $0.97853 \angle-16.937^{\circ}$ & $0.97853 \angle-16.937^{\circ}$ \\
\hline 10 & $0.97431 \angle-17.135^{\circ}$ & $0.97431 \angle-17.135^{\circ}$ & $0.97431 \angle-17.135^{\circ}$ & $0.97431 \angle-17.135^{\circ}$ \\
\hline 11 & $0.98324 \angle-16.815^{\circ}$ & $0.98324 \angle-16.815^{\circ}$ & $0.98324 \angle-16.815^{\circ}$ & $0.98324 \angle-16.815^{\circ}$ \\
\hline 12 & $0.98359 \angle-17.183^{\circ}$ & $0.98359 \angle-17.183^{\circ}$ & $0.98359 \angle-17.183^{\circ}$ & $0.98359 \angle-17.183^{\circ}$ \\
\hline 13 & $0.97796 \angle-17.264^{\circ}$ & $0.97796 \angle-17.264^{\circ}$ & $0.97796 \angle-17.264^{\circ}$ & $0.97796 \angle-17.264^{\circ}$ \\
\hline 14 & $0.95883 \angle-18.242^{\circ}$ & $0.95883 \angle-18.242^{\circ}$ & $0.95883 \angle-18.242^{\circ}$ & $0.95883 \angle-18.242^{\circ}$ \\
\hline
\end{tabular}


Table A2. Voltage profile of the IEEE 30-bus system (in p.u.).

\begin{tabular}{cccccc}
\hline Bus. & Bus Type/Transformer & $\boldsymbol{Z}_{\text {bus }}$ Method & Newton-Raphson & Gauss-Seidel & Decoupled \\
\hline 1 & Slack & $1.00000 \angle 0.000^{\circ}$ & $1.00000 \angle 0.000^{\circ}$ & $1.00000 \angle 0.000^{\circ}$ & $1.00000 \angle 0.000^{\circ}$ \\
\hline 2 & P-V & $0.97782 \angle-6.035^{\circ}$ & $0.97782 \angle-6.035^{\circ}$ & $0.97782 \angle-6.035^{\circ}$ & $0.97782 \angle-6.035^{\circ}$ \\
\hline 4 & TR3(Pri) & $0.94197 \angle-10.520^{\circ}$ & $0.94197 \angle-10.520^{\circ}$ & $0.94197 \angle-10.520^{\circ}$ & $0.94197 \angle-10.520^{\circ}$ \\
\hline 5 & P-V & $0.94230 \angle-16.185^{\circ}$ & $0.94230 \angle-16.185^{\circ}$ & $0.94230 \angle-16.185^{\circ}$ & $0.94230 \angle-16.185^{\circ}$ \\
\hline 6 & TR1(Pri), TR2(Pri) & $0.93936 \angle-12.555^{\circ}$ & $0.93936 \angle-12.555^{\circ}$ & $0.93936 \angle-12.555^{\circ}$ & $0.93936 \angle-12.555^{\circ}$ \\
\hline 8 & P-V & $0.93991 \angle-13.436^{\circ}$ & $0.93991 \angle-13.436^{\circ}$ & $0.93991 \angle-13.436^{\circ}$ & $0.93991 \angle-13.436^{\circ}$ \\
\hline 9 & TR1(Sec) & $0.97206 \angle-16.077^{\circ}$ & $0.97206 \angle-16.077^{\circ}$ & $0.97206 \angle-16.077^{\circ}$ & $0.97206 \angle-16.077^{\circ}$ \\
\hline 10 & TR2(Sec) & $0.96487 \angle-17.931^{\circ}$ & $0.96487 \angle-17.931^{\circ}$ & $0.96487 \angle-17.931^{\circ}$ & $0.96487 \angle-17.931^{\circ}$ \\
\hline 11 & P-V & $1.00000 \angle-16.077^{\circ}$ & $1.00000 \angle-16.077^{\circ}$ & $1.00000 \angle-16.077^{\circ}$ & $1.00000 \angle-16.077^{\circ}$ \\
\hline 12 & TR3(Sec) & $0.98140 \angle-17.112^{\circ}$ & $0.98140 \angle-17.112^{\circ}$ & $0.98140 \angle-17.112^{\circ}$ & $0.98140 \angle-17.112^{\circ}$ \\
\hline 13 & P-V & $1.00000 \angle-17.112^{\circ}$ & $1.00000 \angle-17.112^{\circ}$ & $1.00000 \angle-17.112^{\circ}$ & $1.00000 \angle-17.112^{\circ}$ \\
\hline 27 & TR4(Sec) & $0.94484 \angle-17.806^{\circ}$ & $0.94484 \angle-17.806^{\circ}$ & $0.94484 \angle-17.806^{\circ}$ & $0.94484 \angle-17.806^{\circ}$ \\
\hline 28 & TR4(Pri) & $0.93519 \angle-13.274^{\circ}$ & $0.93519 \angle-13.274^{\circ}$ & $0.93519 \angle-13.274^{\circ}$ & $0.93519 \angle-13.274^{\circ}$ \\
\hline
\end{tabular}

\section{References}

1. Ding, T.; Liu, S.; Yuan, W.; Bie, Z.; Zeng, B. A two-stage robust reactive power optimization considering uncertain wind power integration in active distribution networks. IEEE Trans. Sustain. Energy 2016, 7, 301-311. [CrossRef]

2. Wang, Y.; Li, F.; Wan, Q.; Chen, H. Reactive power planning based on fuzzy clustering, gray code, and simulated annealing. IEEE Trans. Power Syst. 2011, 26, 2246-2255. [CrossRef]

3. Singh, H.; Srivastava, L. Recurrent multi-objective differential evolution approach for reactive power management. IET Gener. Transm. Distrib. 2016, 10, 192-204. [CrossRef]

4. Zhang, C.; Chen, H.; Ngan, H.; Liang, Z.; Guo, M.; Hua, D. Solution of reactive power optimisation including interval uncertainty using genetic algorithm. IET Gener. Transm. Distrib. 2017, 11, 3657-3664. [CrossRef]

5. Mukherjee, A.; Mukherjee, V. Solution of optimal reactive power dispatch by chaotic krill herd algorithm. IET Gener. Transm. Distrib. 2015, 9, 2351-2362. [CrossRef]

6. Shi, H.; Wen, H.; Hu, Y.; Jiang, L. Reactive power minimization in bidirectional DC-DC converters using a unified-phasor-based particle swarm optimization. IEEE Trans. Power Electron. 2018, 33, 10990-11006. [CrossRef]

7. Dai, C.; Chen, W.; Zhu, Y.; Zhang, X. Seeker optimization algorithm for optimal reactive power dispatch. IEEE Trans. Power Syst. 2009, 24, 1218-1231.

8. Raj, S.; Bhattacharyya, B. Optimal placement of TCSC and SVC for reactive power planning using whale optimization algorithm. Swarm Evol. Comput. 2018, 40, 131-143. [CrossRef]

9. Shaheen, A.M.; El-Sehiemy, R.A.; Farrag, S.M. Integrated strategies of backtracking search optimizer for solving reactive power dispatch problem. IEEE Syst. J. 2018, 12, 424-433. [CrossRef]

10. Raha, S.B.; Mandal, K.K.; Chakraborty, N. Hybrid SMES based reactive power dispatch by cuckoo search algorithm. IEEE Trans. Ind. Appl. 2019, 55, 907-917. [CrossRef]

11. Amrane, Y.; Boudour, M.; Belazzoug, M. A new optimal reactive power planning based on differential search algorithm. Int. J. Electr. Power Energy Syst. 2015, 64, 551-561. [CrossRef]

12. Huang, W.; Sun, K.; Qi, J.; Ning, J. Optimisation of dynamic reactive power sources using mesh adaptive direct search. IET Gener. Transm. Distrib. 2017, 11, 3675-3682. [CrossRef]

13. Sheng, W.; Liu, K.; Liu, Y.; Ye, X.; He, K. Reactive power coordinated optimisation method with renewable distributed generation based on improved harmony search. IET Gener. Transm. Distrib. 2016, 10, 3152-3162. [CrossRef]

14. López, J.C.; Vergara, P.P.; Lyra, C.; Rider, M.J.; Silva, L.C.P.D. Optimal operation of radial distribution systems using extended dynamic programming. IEEE Trans. Power Syst. 2018, 33, 1352-1363. [CrossRef]

15. Zhou, E.; Hu, J. Gradient-based adaptive stochastic search for non-differentiable optimization. IEEE Trans. Autom. Control 2014, 59, 1818-1832. [CrossRef] 
16. Nie, Y.; Du, Z.; Li, J. AC-DC optimal reactive power flow model via predictor-corrector primal-dual interior-point method. IET Gener. Transm. Distrib. 2013, 7, 382-390. [CrossRef]

17. Zhang, C.; Chen, H.; Liang, Z.; Guo, M.; Hua, D.; Ngan, H. Reactive power optimization under interval uncertainty by the linear approximation method and its modified method. IEEE Trans. Smart Grid 2018, 9, 4587-4600. [CrossRef]

18. Lin, C.; Wei, H.; Hou, W.; Tan, J. Linear inequalities convex transformation for optimal reactive power flow model based on MISOCP relaxations. IET Gener. Transm. Distrib. 2018, 12, 1589-1594. [CrossRef]

19. Deng, Z.; Liu, M.; Ouyang, Y.; Lin, S.; Xie, M. Multi-objective mixed-integer dynamic optimization method applied to optimal allocation of dynamic Var sources of power systems. IEEE Trans. Power Syst. 2018, 33, 1683-1697. [CrossRef]

20. Franco, J.F.; Ochoa, L.F.; Romero, R. AC OPF for smart distribution networks: An efficient and robust quadratic approach. IEEE Trans. Smart Grid 2018, 9, 4613-4623. [CrossRef]

21. Bhattacharyya, B.; Babu, R. Teaching learning based optimization algorithm for reactive power planning. Int. J. Electr. Power Energy Syst. 2016, 81, 248-253. [CrossRef]

22. Vita, V. Development of a decision-making algorithm for the optimum size and placement of distributed generation units in distribution networks. Energies 2017, 10, 1433. [CrossRef]

23. Nguyen, Q.; Padullaparti, H.V.; Lao, K.; Santoso, S.; Ke, X.; Samaan, N. Exact optimal power dispatch in unbalanced distribution systems with high PV penetration. IEEE Trans. Power Syst. 2019, 34, 718-728. [CrossRef]

24. Galvani, S.; Hagh, M.T.; Sharifian, M.B.B.; Mohammadi-Ivatloo, B. Multiobjective predictability-based optimal placement and parameters setting of UPFC in wind power included power systems. IEEE Trans. Ind. Inform. 2019, 15, 878-888. [CrossRef]

25. Zeng, X.; Tao, J.; Zhang, P.; Pan, H.; Wang, Y. Reactive power optimization of wind farm based on improved genetic algorithm. Energy Procedia 2012, 14, 1362-1367. [CrossRef]

26. Agundis-Tinajero, G.; Aldana, N.L.D.; Luna, A.C.; Segundo-Ramírez, J.; Visairo-Cruz, N.; Guerrero, J.M.; Vazquez, J.C. Extended-optimal-power-flow-based hierarchical control for islanded AC microgrids. IEEE Trans. Power Electron. 2019, 34, 840-848. [CrossRef]

27. Begovic, M.M.; Kim, I. Distributed renewable PV generation in urban distribution networks. In Proceedings of the 2011 IEEE Power Systems Conference and Exposition, Phoenix, AZ, USA, 20-23 March 2011.

28. Kim, I.; Begovic, M.; Jeong, H.; Crittenden, J. Impact of photovoltaic distributed generation on generation resource allocation. In Proceedings of the 2013 46th Hawaii International Conference on System Sciences, Wailea, Maui, HI, USA, 7-10 January 2013; pp. 2230-2236.

29. Kim, I.; Begovic, M. On impact of randomly distributed PV systems on distribution networks. In Proceedings of the 2016 49th Hawaii International Conference on System Sciences, Koloa, HI, USA, 5-8 January 2016; pp. 2418-2425.

30. Kim, I.; Harley, R.G.; Regassa, R. Optimal distributed generation allocation on distribution networks at peak load and the analysis of the impact of volt/var control on the improvement of the voltage profile. In Proceedings of the 2014 North American Power Symposium, Pullman, WA, USA, 7-9 September 2014.

31. Thallam, R.S.; Suryanarayanan, S.; Heydt, G.T.; Ayyanar, R. Impact of interconnection of distributed generation of electric distribution systems-A dynamic simulation perspective. In Proceedings of the IEEE Power Engineering Society General Meeting, Montreal, QC, Canada, 18-22 June 2006.

32. Vita, V.; Alimardan, T.; Ekonomou, L. The impact of distributed generation in the distribution networks' voltage profile and energy losses. In Proceedings of the 2015 IEEE European Modelling Symposium, Madrid, Spain, 6-8 October 2015; pp. 260-265.

33. Kim, I.; Harley, R.G.; Regassa, R.; Valle, Y.D. The effect of the Volt/VAr control of photovoltaic systems on the time-series steady-state analysis of a distribution network. In Proceedings of the 2015 Clemson University Power Systems Conference (PSC), Clemson, SC, USA, 10-13 March 2015.

34. Goldberg, D.E. Genetic Algorithms in Search, Optimization, and Machine Learning; Addison-Wesley: Boston, MA, USA, 1989.

35. Kim, I. Optimal distributed generation allocation for reactive power control. IET Gener. Transm. Distrib. 2017, 11, 1549-1556. [CrossRef] 
36. Amini, M.H.; Jaddivada, R.; Hoseinzadeh, B.; Mishra, S.; Mozafar, M.R. Optimal SVC allocation in power systems for loss minimization and voltage deviation reduction. In Sustainable Interdependent Networks: From Theory to Application; Springer International Publishing: Cham, Switzerland, 2018; pp. 221-232.

37. Kılıç, U.; Ayan, K.; Arifoğlu, U. Optimizing reactive power flow of HVDC systems using genetic algorithm. Int. J. Electr. Power Energy Syst. 2014, 55, 1-12. [CrossRef]

38. Abdelkader, A.; Rabeh, A.; Ali, D.M.; Mohamed, J. Multi-objective genetic algorithm based sizing optimization of a stand-alone wind/PV power supply system with enhanced battery/supercapacitor hybrid energy storage. Energy 2018, 163, 351-363. [CrossRef]

39. Kim, I.; Harley, R.G. Examination of the effect of the reactive power control of photovoltaic systems on electric power grids and the development of a voltage-regulation method that considers feeder impedance sensitivity. Electr. Power Syst. Res. 2020, 180, 106130. [CrossRef]

40. Brown, H.E.; Carter, G.K.; Happ, H.H.; Person, C.E. Power flow solution by impedance matrix iterative method. IEEE Trans. Power Appar. Syst. 1963, 82, 1-10. [CrossRef]

41. Dugan, R.C.; Arritt, R.F.; Smith, J.; Rylander, M. OpenDSS Training Workshop; University of North Carolina at Charlotte: Charlotte, NC, USA, 2013.

42. Houck, C.R.; Joines, J.A.; Kay, M.G. A genetic algorithm for function optimization: A MATLAB implementation. Tech. Rep. 1995, 95, 1-10.

43. Dabbagchi, I. IEEE 14-Bus System. 1993. Available online: http://labs.ece.uw.edu/pstca/pf14/pg_tca14bus.htm (accessed on 8 February 2019).

44. Working Group on a Common Format for Exchange of Solved Load Flow Data, Common format for exchange of solved load flow data. IEEE Trans. Power Appar. Syst. 1973, 92, 1916-1925.

45. Dabbagchi, I. IEEE 30-Bus System. 1993. Available online: http://www.ee.washington.edu/research/pstca/ pf30/pg_tca30bus.htm (accessed on 8 February 2019).

46. Dabbagchi, I. IEEE 57-Bus System. 1993. Available online: http://labs.ece.uw.edu/pstca/pf57/pg_tca57bus.htm (accessed on 8 February 2019).

47. Kim, I. Impact of stochastic renewable distributed generation on urban distribution networks. In Doctor of Philosophy, Electrical and Computer Engineering; Georgia Institute of Technology: Atlanta, GA, USA, 2014.

48. Pregelj, A. Impact of distributed generation on power network operation. In Doctoral Dissertation; Georgia Institute of Technology: Atlanta, GA, USA, 2003.

49. De Jong, K.A. An Analysis of the Behavior of a Class of Genetic Adaptive Systems. Ph.D. Thesis, University of Michigan, Ann Arbor, MI, USA, 1975. 